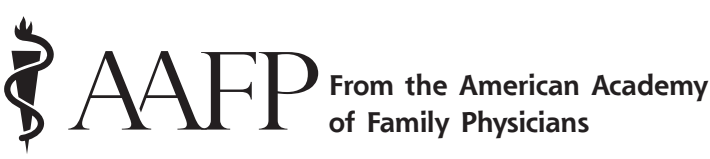

Ann Fam Med 2016;14:483-484. doi: 10.1370/afm.1978.

\section{PROPOSED MACRA IMPLEMENTATION RULE MISSES MARK, AAFP TELLS CMS}

On April 28, 2016, the US Department of Health and Human Services (HHS) released a long-awaited proposed rule intended to guide implementation of the Medicare Access and CHIP Reauthorization Act (MACRA). When fully implemented, MACRA will, by all accounts, drastically change the way CMS pays physicians to take care of their Medicare patients.

The proposed rule, (https:/www.gpo.gov/fdsys/ pkg/FR-2016-05-09/pdf/2016-10032.pdf) titled "Medi-

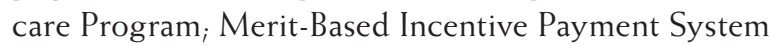
(MIPS) and Alternative Payment Model (APM) Incentive Under the Physician Fee Schedule, and Criteria for Physician-Focused Payment Models," was published in the May 9 Federal Register.

Nearly every day since the proposed rule was released, a team of AAFP payment and policy experts has scoured the details of this complicated proposal looking for ways to ease family physicians' transition into a variety of new payment models.

The fruits of that combined effort are evident in a 100-plus page letter (http://www.aafp.org/dam/AAFP/ documents/advocacy/payment/medicare/LT-CMSMACRAComments-062416.pdf) brimming with recommendations for CMS Acting Administrator Andy Slavitt to consider.

Family physicians looking for a simpler, slimmeddown version of the AAFP's comments can explore the high points in an executive summary (http://www. aafp.org/dam/AAFP/documents/advocacy/payment/ medicare/ES-CMS-MACRARule-062416.pdf).

AAFP Board Chair Robert Wergin, MD, of Milford, Nebraska, began the June 24 letter by expressing the AAFP's overall support for MACRA. "We believe it was intended to strengthen primary care and make primary care a strong foundation" on which to build health care payment and delivery reform, he said.

But the importance of a successful implementation of the final rule cannot be overstated, he added.

With that in mind, CMS needs to "step back and reconsider" its approach to a proposed rule that is "overly complex and burdensome" for all physicians, said Wergin.

"The implementation of MACRA will impact our health care system for years to come, and it must be done thoughtfully, carefully and as simply as possible."
This proposed rule "falls short of these goals," he concluded.

The Academy covered a lot of ground in its response to $\mathrm{CMS}^{\prime}$ proposed rule; a few red-hot issues most pertinent to family physicians are covered here.

\section{Virtual Groups}

The AAFP came down hard on $\mathrm{CMS}^{\prime}$ plan to delay implementation of virtual groups until 2018. The concept of virtual groups-as related to MIPS—would allow individual physicians or group practices of 10 or fewer eligible professionals to join forces as a virtual group during a MIPS performance period.

Wergin pointed out that CMS would run afoul of MACRA by not having this process in place by 2017 .

But more importantly, lack of the virtual group option in 2017 would negatively affect many family physicians.

This inaction on the part of CMS means that "solo and small group physicians who had been counting on the virtual group option to be successful under MIPS will not have the opportunity," said Wergin.

He noted that more than a few family physicians had expressed enthusiasm for this opportunity, and from their conversations with the AAFP, it was clear that members "viewed it as an option to band together to share resources while maintaining their independence."

Taking this option off the table in 2017 will harm practices that were otherwise ready to engage with MACRA, said Wergin. "We are concerned they will be the hardest hit when CMS implements MIPS in 2017," he added.

The AAFP strongly urged CMS to create a "safe harbor" to exempt solo and small group practices (defined by the AAFP as 5 or fewer clinicians) from MIPS until the framework for virtual groups is in place.

\section{MIPS Performance Period}

The AAFP reiterated an earlier appeal to CMS regarding the initial performance period start date for MACRA.

"The AAFP urgently and strongly calls on CMS to consider using 2018 as the initial assessment period for MACRA, and under no circumstances should the initial performance period start any earlier than July 1 , 2017," said Wergin.

Wergin pointed out that if the final rule is issued around November 1, 2016, with a start date of January 1,2017 , physicians would have only 2 months to do a lot of prep work, including selecting quality measures and identifying clinical practice improvement activities.

He suggested that 2017 be designated as a reporting preparation year and 2018 "be a year of judgment." 
The AAFP also refuted the notion that 2-year-old data were clinically actionable or meaningful to physicians and urged CMS to find a way to provide feedback to physicians within 1 year or less.

"The law mandates that the performance period and payment period be as close together as possible, and a 2-year gap simply ignores this legislative mandate," said Wergin.

\section{Quality Measures}

The AAFP stood its ground on previous recommendations regarding the use of quality measures.

"The AAFP supports reasonable and achievable quality improvement programs that promote continuous quality improvement and measure patient experiences. The AAFP opposes an approach that requires physicians to report on a complex set of measures that do not impact or influence the quality of care provided to patients," said Wergin.

He insisted that all measures used in MIPS and APMs "be clinically relevant, harmonized among all public and private payers, and minimally burdensome to report."

Wergin called on CMS to use the core measure sets developed by the Core Quality Measures Collaborative, (http://www.aafp.org/news/practice-professionalissues/20160216corequality.html) a multistakeholder group of which the AAFP is an active member.

In addition, he expressed concern about "parity in reporting" across all specialty and subspecialty physician groups in regard to quality measure sets related to MIPS.

"If CMS requires a lower number of quality measures for particular specialty groups in MIPS, that lower number of measures for reporting should be available to all MIPS-eligible clinicians," said Wergin.

"Reducing what seem to be reasonable/achievable requirements for some specialties will result in a continued disproportionate burden on those specialties (such as family medicine) that have been engaged in quality measurement and development," he added.

\section{Medical Homes}

The AAFP has been a leader in the medical home movement dating back to 2004 when the Joint Principles of the Patient-Centered Medical Home (PCMH) (http://www.aafp.org/dam/AAFP/documents/practice_ management/pcmh/initiatives/PCMHJoint.pdf) were developed by the Academy and 3 other physician organizations and officially adopted by the groups in 2007 .

With that background in mind, it's no surprise that Wergin insisted that physicians not be forced to "pay a 3rd-party accrediting body to receive recognition as an advanced primary care practice," such as a PCMH.
The AAFP suggested that CMS "use a deeming authority to grant any entity which meets the necessary criteria as a PCMH accreditor to be an approved program," and encouraged the inclusion of state-based, payer-sponsored and regional PCMH recognition programs.

Furthermore, the Academy adamantly opposes CMS' proposed financial standard for the medical home model and called its inclusion in the proposed rule an "arbitrary imposition of financial risk placed upon clinicians in the models," said Wergin.

"This is an egregious misinterpretation of the law, which was designed to protect and foster medical homes," he added.

Wergin called the medical home model "the crux of a value-based health care system" and a concept that has been proven to reduce spending and utilization.

\section{Additional Issues}

The AAFP made several other important comments on provisions in the proposed rule:

- Wergin objected to $\mathrm{CMS}^{\prime}$ application of the total per capita cost of care and Medicare spending per beneficiary measures to primary care physicians who are not part of an advanced APM.

- The current proposal for "advancing care information" is too complex and, in fact, "missed the mark in a major way."

- CMS' definition of a "medical home model expanded" is too narrow and a deterrent to physicians looking to participate in the APM program.

- The AAFP is concerned about CMS' proposal to implement a "MIPS APM" category.

Regarding the final bullet point, Wergin said, "Unfortunately, throughout this section of the proposed rule, there are so many different rules and exceptions that no practicing physician could reasonably understand and report accurately to get a fair payment."

Sheri Porter AAFP News 